\title{
An Overview of Cold Spray Additive Technology in Australia for Melt-less Manufacture of Titanium
}

\author{
Saden H. Zahiri, Stefan Gulizia, Leon Prentice \\ Commonwealth Scientific and Industrial Research Organisation (CSIRO) Manufacturing, Clayton, \\ Victoria 3168, Australia
}

\begin{abstract}
$\underline{\text { Abstract }}$
The difficulty in significantly reducing the cost of titanium products is partly related to the high cost of manufacturing. This includes additive manufacturing; e.g. Electron Beam Melting (EBM) and Selective Laser Melting (SLM), as well as traditional approaches that are based on a melting process. In particular, the cost of titanium powder has placed limits on the application of additive manufacturing approaches that involve melting to broader commercial applications beyond military, aerospace and implants. More than a decade ago, Australia adopted cold spray technology as a meltless additive manufacturing technique to fabricate titanium through a strategic initiative at Commonwealth Scientific and Industrial Research Organisation (CSIRO). The high deposition rate, $\sim 100$ times faster than the other additive technologies, and the solid state deposition were amongst the rationales for investment in cold spray technology. A combination of carefully designed experiments and sophisticated 3D models were developed to assess performance of the current industrial-scale cold spray systems for commercial clients. The success and challenges of this solid state deposition technology will be detailed with a focus on real industrial impact. The future development of melt-less titanium manufacturing using cold spray will be discussed with consideration of commercial and environmental benefits.
\end{abstract}

\section{Introduction}

Rapid deposition of titanium solid particles without melting was an important rational for many forward looking companies to adopt cold spray additive technology in Australia and around the globe. In recent years, this particularly has created interests in Australian share market (ASX) through creation of companies such as Titomic Ltd with other companies such as RUAG Australia Pty Ltd and Kinetic Elements Pty Ltd using cold spray additive process. In cold spray additive process titanium powder $(\sim 5-70 \mu)$ is accelerated to well above supersonic speeds $(500-1500 \mathrm{~m} / \mathrm{s})$ in order to create a metallurgical bond with the substrate surface under shock load [1-3] (Fig. 1). A propellant gas, generally nitrogen or helium at high pressure and temperature is used to accelerate particles [4]. 
Bonding takes place due to intense particle deformation during impact, rather than in-flight melting, which has the significant benefit of avoiding phase transformation and high temperature reactions in titanium. Unlike other additive technologies such as Electron Beam Melting (EBM) [5], confined space is not required promoting commercial viability of the cold spray manufactured titanium.

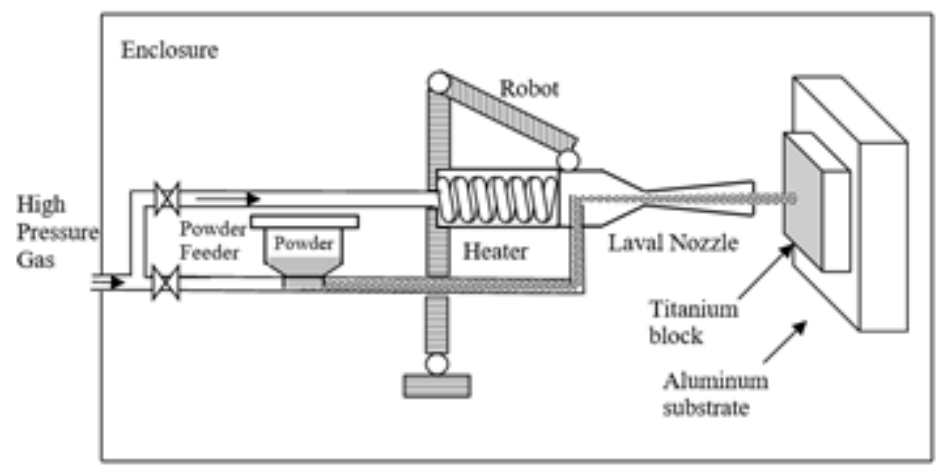

Fig. 1 Schematic diagram for cold spray system presenting deposition of Titanium on Aluminium substrate.

The challenges in relation to cold spray rapid (nanoseconds) deposition are mainly related to optimisation of the deposition conditions and mechanical properties of the deposited titanium. Optimisation of at least 14 parameters for successful deposition is complicated and costly. Some of the important processing parameters are career gas temperature, gas pressure, standoff distance, particle size distribution, nozzle geometry, powder feed rate etc. Recently [6], a 3D multicomponent model was developed via a detailed calibration and validation process to overcome some of the difficulties in optimisation of all cold spray parameters. The model holistically determines state of titanium particles, including velocity, temperature and location, from the injection point to the moment of deposition with consideration of earlier studies [7-10]. The coupling of high speed propellant gas exiting the de Laval nozzle with the surrounding, stationary air provides more realistic predictions via 'multicomponent' simulation. The details of the developed 3D model can be found elsewhere [6,11]. In the present study, the model outcomes as a capability to compare the current industry scale cold spray systems performance is presented. This capability has already been successfully examined at CSIRO to improve cold spray system design and to quantify the key processing parameters in regards to titanium additive manufacturing. An example of such application is presented with some highlights relevant to the real titanium industry.

\section{$\underline{\text { Numerical analysis }}$}


A widely used two equation $k-\varepsilon$ turbulence model, based on Reynolds-Average Navier-Stokes (RANS)-type transport equations for compressible fluid flow, was utilized for the numerical analysis. A commercially available computational fluid dynamics (CFD) package, ANSYS ${ }^{\mathrm{TM}}$ CFX Solver ${ }^{\circledR}$ under Workbench $^{\mathrm{TM}}$ v14.5.7 (ANSYS, Inc. Canonsburg, Pittsburgh, PA, USA) was employed with details explained elsewhere [11]. The CFD program was based on the finite volume method to solve the Navier-Stokes equations which were governed by the continuity equation, momentum equation and total energy equation [11]. The 3D model was developed with consideration of other 1D and 2D numerical studies [7-10] to estimate velocity, temperature and location of impact for cold spray deposits. Calibration and validation of the 3D model including computational domain with titanium particles and 3D hexahedral mesh were based on earlier experimentations [12].

\section{Computational domain and boundary conditions}

The 3D computational domain in the present study consists of a solid nozzle, high pressure nitrogen, surrounding air and solid substrate. The substrate was modelled as a 70x70 mm, $5 \mathrm{~mm}$ thick titanium square. The surrounding domain was created as a cylinder with $400 \mathrm{~mm}$ diameter and 361.5 $\mathrm{mm}$ length. It comprised three surfaces; a vertical face at nozzle pre-chamber section, a vertical face behind the substrate, and main peripheral surface filled with ambient air. Dimensions of commercially available tungsten carbide (WC) de Laval nozzles from Impact Innovation ${ }^{\circledR}$ (II) and Plasma Giken ${ }^{\circledR}$ (PG) were precisely measured. This information with important nozzle dimensions (Table 1) was used for simulations including water flow to cool nozzles (18 1/min for II nozzle and 8 1/min for PG nozzle) recommended by cold spray system providers.

Configuration $\quad$ Impact Innovation ${ }^{\circledR} \quad$ Plasma Giken ${ }^{\circledR} \mathrm{mm}$

Throat diameter

Divergent section length

Exit diameter

6.16

11.5

Table 1. Critical nozzle dimensions for 3D simulation of II and PG cold spray systems.

\section{Computational grid}


Meshing was performed on ANSYS ${ }^{\circledR}$ ICEMCFD ${ }^{\circledR}$ v14.5.7 (ANSYS, Inc. Canonsburg, Pittsburgh, PA, USA) using the blocking method with hexahedral elements for all fluid and solid domains to provide improved convergence. A combination of smaller and larger grid element sizes were considered during mesh optimization in order to achieve numerical accuracy with minimum computation time. The transition of meshing between fluid and solid domains is generally set at the minimum [13] as large variations at the interface may disturb the convergence rate. Considering this, an optimal mesh structure was built for critical regions where severe parameter variations were expected. These regions were mainly the cold spray nozzle throat area, the jet expansion region at the nozzle exit and the jet impingement zone in front of the substrate. The largest mesh element size of $52.3 \mathrm{~mm}$ was built in $\mathrm{th}$ e cylindrical surrounding air domain to reduce the overall computation time without compromising accuracy. An element size of $0.018 \mathrm{~mm}$ was found to be suitable for the throat region to incorporate sudden changes in gas compression-expansion conditions. For the transition between near-wall and free stream turbulence models, inflation layers with $\mathrm{y}+$ of about 8 were chosen adjacent to the wall boundaries $[14,15]$.

The grid-independency test was performed by comparing the propellant gas velocity at the nozzle exit with grid sizes that were approximately 50\% finer and coarser. It was found that a finer grid did not contribute to any large variation in the solution. With the coarser grid size, it was difficult to generate a stable solution [16]. The optimal mesh presenting a good compromise between accuracy and overall computation time was reached when less than $2 \%$ difference in the values of propellant gas velocity at the nozzle exit was achieved.

\section{Titanium particles}

Cold spray conditions $700^{\circ} \mathrm{C}, 3.5 \mathrm{MPa}$ (35 bar) and $30 \mathrm{~mm}$ standoff distance with nitrogen as carrier gas were chosen to reveal trajectory of the titanium particles. These conditions were chosen as an example to demonstrate variations in the performance of the II and PG cold spray systems and to make results commercially indifferent. The interaction between solid particles and propellant gas in the 3D model was defined using the Lagrangian particle tracking method. Earlier studies have implemented this method to simulate particle transport in the cold spray process [17-19]. The $3 \mathrm{D}$ model simulated the velocity and temperature for $(2 \mathrm{~kg} / \mathrm{hr})$ spherical titanium particles as per a typical particle size distribution $(5,12,26$ and $41 \mu \mathrm{m})$ for cold spray deposition $[6,20,21]$. The injection position of the powder in the stagnation zone was similar to the powder injection location for cold spray systems of this study. It is worth mentioning that the interaction between solid particles and propellant gas was fully coupled and involved intensive momentum and heat transfer. Details of the governing equations of particle transport including the equation of motion for particle acceleration, drag force, drag coefficient and equation of heat transfer can be found elsewhere [22].

\section{$\underline{\text { Results }}$}


The 3D model qualitative results for II and PG cold spray systems are shown in Fig. 2. Under identical conditions both systems presented significant increase in titanium particles velocity beyond the nozzle throat. The predicted heat transfer profiles revealed higher temperature at the tip of the PG compared to the II system. The computed trajectory of particles velocity in the II system nozzle (Fig. 3a) revealed that titanium particles acceleration continued beyond the nozzle exit. In contrast, fine $(5 \mu \mathrm{m})$ particles were decelerated after departure from the PG nozzle (Fig. 3b) due to presence of a shock wave at the tip of the nozzle.

Fig 4 shows the simulation outcomes for the particles temperature from the injection point to the moment of impact. In the stagnation zone and before the nozzles throat, the injected particles reduced the gas temperature $\sim 50^{\circ} \mathrm{C}$ in the II and PG nozzles. The largest $41 \mu \mathrm{m}$ particles were unable to reach gas temperature in both nozzles. The shock wave at the tip of the PG nozzle (Fig. $4 \mathrm{~b}$ ) increased the gas temperature to $480^{\circ} \mathrm{C}$ that was $360^{\circ} \mathrm{C}$ more than the II nozzle. In contrast, the carrier gas temperature on the surface of the PG system substrate was $\sim 300^{\circ} \mathrm{C}$ less than the II indicating less thermal stress on the deposited particles using the PG system. These results demonstrate a complex relationship between the commercial cold spray systems and the way in which deposited titanium is additively manufactured. 


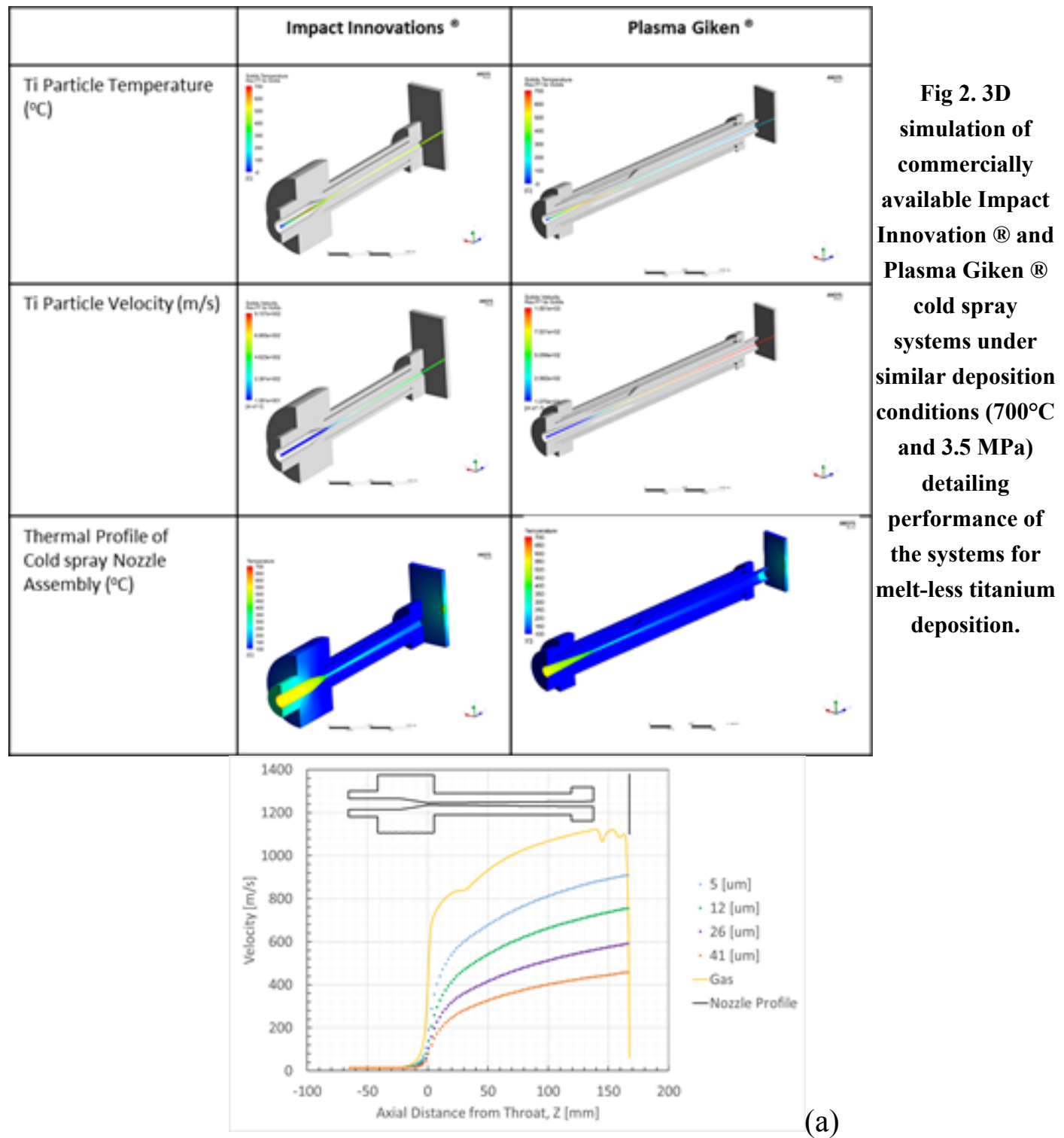




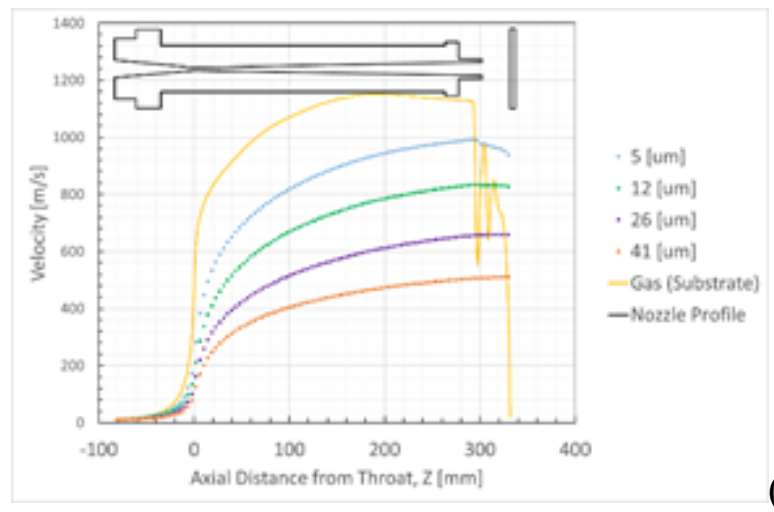

(b)

Fig 3 Estimated results for II cold spray system (a) velocity and (b) temperature of titanium particles from the injection point to the moment of impact onto the substrate.

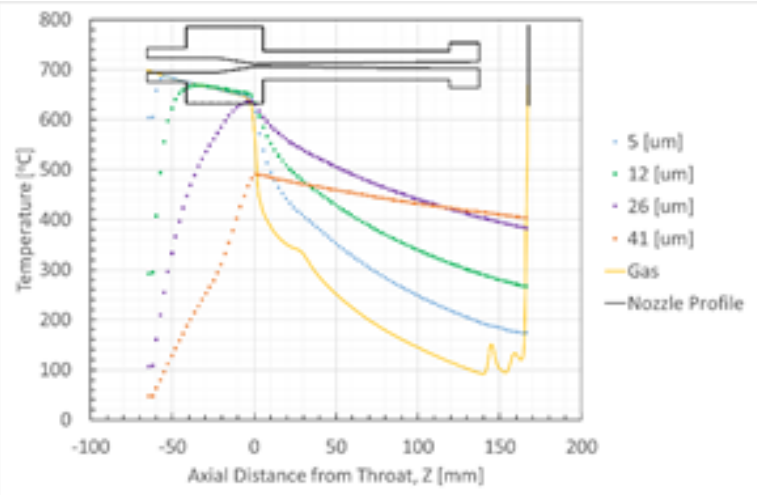

(a)

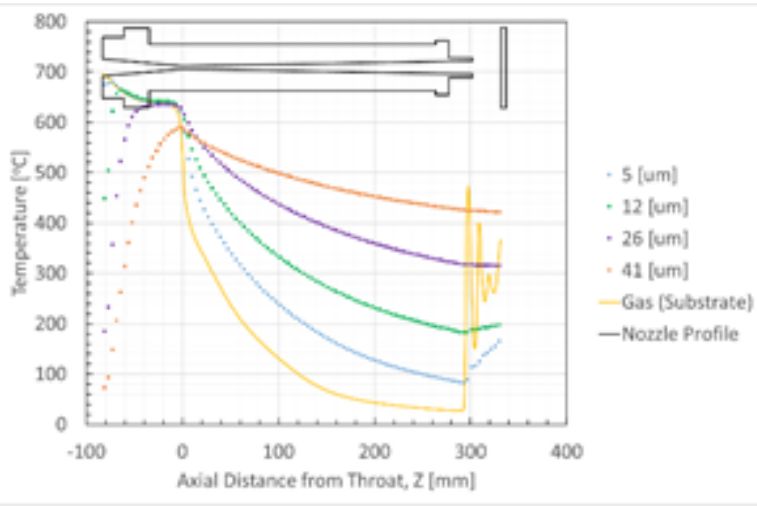

(b) 
Fig 4 Estimated results for PG cold spray system (a) velocity and (b) temperature of titanium particles from the injection point to the moment of impact onto the substrate.

\section{$\underline{\text { Discussion }}$}

In order to evaluate the II and PG cold spray systems performance, titanium particles velocity and temperature were compared with the estimated critical velocity (Fig. 5). The critical velocity (Vc) represents the minimum value for velocity of titanium particles to deposit and bond successfully [23]. Thus, achievement of a particle velocity that is above the Vc contributes to improved cold spray bonding and mechanical properties through extra deformation of particles and densification. Fig. 5 shows that the PG nozzle accelerated titanium particles more than the II system. In contrast, the II nozzle increased 12 and $26 \mu \mathrm{m}$ particles temperature more than the PG nozzle. This represented a slightly lower Vc value for the II nozzle. A comparison of the Vc and particle velocity curves showed that the possibility of $20 \mu \mathrm{m}$ particles depositing under PG nozzle configuration was higher than the II nozzle. For conditions of this study, the probability of deposition for the largest particles (i.e. $40 \mu \mathrm{m}$ ) was limited. In this regard, some highlights and practical examples to optimise commercial cold spray systems of this study are discussed.

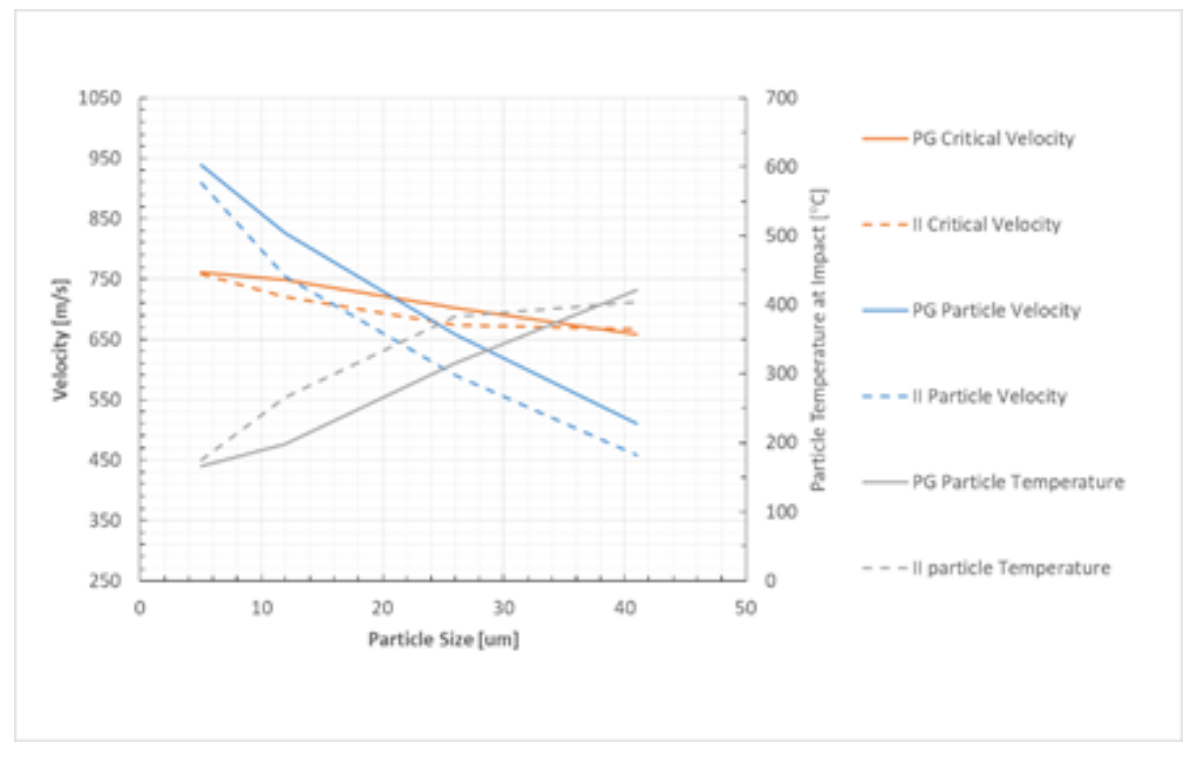

Fig 5 Comparison of the Plasma Giken ${ }^{\circledR}$ and Impact Innovation cold spray systems performance in relation to particle velocity, particle temperature and critical velocity $(\mathrm{Vc})$ for the chosen particle size distribution. 
The hot zone at the tip of the PG nozzle (thermal profile in Fig. 2) was the result of a shock wave occurring at least partially inside the PG nozzle. This increase in temperature did not occur in the II nozzle due to presence of the shock wave further away from the nozzle exit. The PG nozzle shockwave most likely disrupts very fine (submicron) titanium particles promoting nozzle blockage. Further to this, creation of thermal stress at the tip of the nozzle could reduce the nozzle life through crack formation. It is worth noting that the PG nozzle under other cold spray conditions (e.g. higher carrier gas temperature and pressure) may perform differently suggesting utilization of the 3D model to be an integral part of the cold spray deposition.

Trajectory of the particles departure from the II nozzle (Fig. 3a) revealed that titanium particles were accelerating and did not reach their maximum velocity before impact onto the substrate surface. This prediction implied that standoff distance had to be larger than $30 \mathrm{~mm}$ for the II cold spray system to position substrate where particles impact at their maximum velocity. This will contribute to improved densification. Another benefit of increasing the standoff for the II nozzle will be reduction of impinging gas temperature on substrate. Fig 4 shows that the impinging gas temperature on the II nozzle was $\sim 300^{\circ} \mathrm{C}$ higher than the PG nozzle. This indicates that under this conditions the deposited titanium using II system exhibits higher thermal stress compared to the PG system.

The model predicted that optimisation (i.e. extension) of the II and PG nozzles stagnation zone was required to allow sufficient time for particles to reach gas temperature. Fig. 4 shows that particularly larger particles (e.g. $+30 \mu \mathrm{m})$ temperature required to reach the carrier gas temperature. An increase in titanium particle temperature results in a reduction in Vc (Fig. 5) contributing to improved cold spray bond formation and densification [23]. The II cold spray system has commercially available extended stagnation zone for longer exposure of large particles to the carrier gas. This capability yet to be available for the PG system.

The mixed results for two commercially available cold spray systems were examples that show cased complicated optimisation of cold spray titanium deposition. Over the last decade, it was realised that execution of the experimental procedures to achieve similar outcomes to the calibrated and validated 3D model were highly costly and in some cases extremely difficult. The model capabilities have already been used to assist local and international companies to develop new and cost effective additive technologies for titanium. Further development of the 3D model to include titanium particle bond formation in relation to the predicted particle history is paramount to enhance collaboration and cold spray technology take up in progressive titanium manufacturing community.

\section{Conclusion}


The development of cold spray additive technology through collaboration highlighted the benefits and complexities of cold spray additive technology to cost effectively manufacture titanium. An example to overcome some of the complexities of the cold spray solid state deposition using a calibrated and validated 3D model was presented. The results were mixed for a chosen cold spray conditions applied to Impact Innovation ${ }^{\circledR}$ and Plasma Giken ${ }^{\circledR}$ industrial cold spray systems. The PG nozzle accelerated particles to higher velocity whilst the II system nozzle provided higher temperature for particles. Under identical conditions, the II system required larger standoff distance to reduce thermal stress and to achieve the highest particles velocity before impact. These predictions with detailed information on performance of the cold spray systems have already assisted companies engaged in cold spraying and created further opportunities to solve real challenges for titanium industry through collaboration.

\section{Acknowledgements}

Authors would like to acknowledge contribution of Dr Peter Cook from CSIRO for part of the modelling outcomes.

\section{References}

[1] S. Cadney, M. Brochu, P. Richer, and B. Jodoin, Surf. Coatings Technol. 202 (2008) 2801-2806.

[2] D. Kotoban, S. Grigoriev, A. Okunkova, and A. Sova, Surf. Coatings Technol. 309 (2017) 951958.

[3] R.E. Blose, B.H. Walker, R.M. Walker, and S.H. Froes, Met. Powder Rep. 61 (2006) 30-37.

[4] A. Papyrin, V. Kosarev, S. Klinkov, A. Alkimov, and V. Fomin, “Cold Spray Technology,” A. Papyrin, Ed., 1st ed., Elsevier Ltd, (2007).

[5] D. Riedlbauer, T. Scharowsky, R.F. Singer, P. Steinmann, C. Körner, and J. Mergheim, Int. J. Adv. Manuf. Technol. (2016) 1-9.

[6] M. Faizan-Ur-Rab, S. H. Zahiri, S.H. Masood, M. Jahedi, and R. Nagarajah, CFD Modeling and Simulation in Materials Processing 2016, (Nashville, USA), John Wiley \& Sons, Inc. (2016) 213-220. 
[7] S. Guetta, M.H. Berger, F. Borit, V. Guipont, M. Jeandin, and M. Boustie, J. Therm. Spray Technol. 18 (2009) 331-342.

[8] W.Y. Li, C. Zhang, C.-J. Li, and H. Liao, J. Therm. Spray Technol. 18 (2009) 921-933.

[9] W.Y. Li and W. Gao, Appl. Surf. Sci. 255 (2009) 7878-7892.

[10] W.-Y. Li, H. Liao, C.-J. Li, H.-S. Bang, and C. Coddet, Appl. Surf. Sci., 253 (2007) 5084-5091.

[11] M. Rab, S. Zahiri, S. Masood, M. Jahedi, and R. Nagarajah, 5 (2015) 688-708.

[12] S.H. Zahiri, T.D. Phan, S.H. Masood, and M. Jahedi, J. Therm. Spray Technol. 23 (2014) 919933.

[13] P.R. Spalart, Heat Fluid Flow, 21 (2000) 252-263.

[14] H. Grotjans and F. Menter, Wall Functions for General Application \{CFD\} Codes., (1998).

[15] D.C. Wilcox, “Turbulence Modeling for CFD," 3rd ed., DCW Industries, La Canada Flintridge CA 91011, (2000).

[16] M. Karimi, G.W. Rankin, and B. Jodoin, Shock-Wave Induced Spraying: Gas and Particle Flow and Coating Analysis, Surf. Coatings Technol. 207 (2012) 435-442.

[17] M. Faizan-Ur-Rab, S.H. Zahiri, S.H. Masood, M. Jahedi, and R. Nagarajah, J. Therm. Spray Technol., 26 (2017) 941-957.

[18] M. Karimi, A. Fartaj, G. Rankin, D. Vanderzwet, W. Birtch, and J. Villafuerte, J. Therm. Spray Technol. 15 (2006) 518-523.

[19] M. Meyer and R. Lupoi, Mech. Sci, 6 (2015) 127-136.

[20] B. Samareh and A. Dolatabadi, J. Therm. Spray Technol., 16 (2007) 634-642.

[21] M. Faizan-Ur-Rab, S.H. Zahiri, S.H. Masood, T.D. Phan, M. Jahedi, and R. Nagarajah, Mater. Des., 89 (2016) 1227-1241.

[22] M. Faizan-Ur-Rab, S.H. Zahiri, P.C. King, C. Busch, S.H. Masood, M. Jahedi, R. Nagarajah, S. Gulizia, J. Therm. Spray Technol., 26 (2017) 1874-1887.

[23] H. Assadi, F. Ga“rtner, T. Stoltenhoff, H. Kreye, Acta Mater. 51 (2003) 4379-4394. 